\title{
Association between Body Mass Index and Bone Mineral Density in Patients Referred for Dual-Energy $\mathrm{X}$-Ray Absorptiometry Scan in INMAS, Sylhet
}

\author{
Kamun Nahar', Mohammed Mehedi Al Zahid Bhuiyan',Muhammad Sirazul Munir', Habibur Rahman² \\ ${ }^{1}$ Institute of Nuclear Medicine and Allied Science, Sylhet \\ ${ }^{2}$ Sylhet MAG Osmani Medical College, Sylhet
}

Correspondence Address: Dr. Kamrun Nahar, PMO \& Director, Institute of Nuclear Medicine and Allied Sciences (INMAS), Sylhet, E-mail: nahar.nuclear@gmail.com

\begin{abstract}
With an aging population, osteoporosis is increasingly becoming a public health concern. Bangladesh has a high incidence of osteoporosis and occurs among a relatively younger age group than in the developed world. There are several factors that could be associated with bone mineral density (BMD). We are keen to determine the association with BMD and BMI. The study was carried out on 152 patients who were referred to INMAS for dual energy X-ray absorptiometry (DEXA) measurement of bone mineral density (BMD) during the periods of January 2018 to July 2019. BMD was measured at right femoral neck and lumbar spines. Data about age and sex, BMI were recorded. Reporting was done according to the $\mathrm{T}$ score following WHO criteria. Prevalence were compared using chi-squared tests. Among 152 patients, $84.9 \%$ were females and $15.1 \%$ were males. Results showed for right femur that normal bone density in 91 (59.1\%), osteopenia in $54(35.1 \%)$, osteoporosis in $9(5.8 \%)$ and BMD in spine was normal in 57 $(37.0 \%)$ osteopenia in $44(28.6 \%)$, osteoporosis in $53(34.4 \%)$. About $60 \%$ of the study population was normal weight and others were underweighted or overweighed. Status of BMD was associated with BMI in the lumbar spine and femur. In this study group, total $61.2 \%$ and $26.3 \%$ were found low BMD in spine and right femur respectively. In age group $\geq 60$ years, low BMD in spinewas $72.0 \%$ that is $42.29 \%$ higher compare to below 60 years' group (50.6\%).Correlation of BMI with lumbar spine T score, right femur and left femur $\mathrm{T}$ score were measured by Pearson's correlation coefficient test. Positive significant Pearson's correlation was observedbetween BMI with spine T score $(r=0.397 ; \mathrm{p}=<0.001)$, BMI with right femur T score $(\mathrm{r}=0.347 ; \mathrm{p}=<0.001)$ and BMI with left femur T score $(\mathrm{r}=0.382 ; \mathrm{p}=<0.001)$.
\end{abstract}

Keywords: Osteoporosis, Bone mineral density, Dual energy x-ray absorptiometry (DEXA), Body Mass Index

Bangladesh J. Nucl. Med. Vol. 22 No. 2 July 2019

Doi: https://doi.org/10.3329/bjnm.v22i2.51760

\section{INTRODUCTION}

Osteoporosis, which was once considered a disease of the elderly, but now it is occurred in any age whose conventional bone mineral density (BMD) has dropped to a critical threshold (1). Thus, osteoporosis has become a global health problem. The amount of BMD acquired during childhood and adolescence may be important in reducing the risk of osteoporosis in the future. The number of osteoporosis patients has increased every year due to the growth of the elderly population in Bangladesh (2). BMD is a necessary component of the assessment of bone quality and is used to assess the osteoporotic status of the bone for the prevention of osteoporotic fractures. As age increases, the bones become naturally thin as the existing bone breaks down faster than new bone made. As a result, bones calcium and other mineral are reduced and they become lighter, less dense and more brittle in weight (3). Bones can be broken when it becomes thin and weak. Therefore, thicker bones take longer to get osteoporosis (4).

The World Health Organization defines obesity as the Body Mass Index $(B M I) \geq 30 \mathrm{~kg} / \mathrm{m}^{2}$, the overweight as a $\mathrm{BMI}=25$ to $29.9 \mathrm{~kg} / \mathrm{m}^{2}$, and the underweight BMI as $<18.5 \mathrm{~kg} / \mathrm{m}^{2}$. However, the relationship between high BMI and fracture risk is complex. The existence of a positive association between body size and bone mass is well established. Moreover, low body mass index (BMI) is a predictor of increased bone loss at the forearm. Therefore, interest in studying the influence of obesity and overweight on the risk of fracture has recently increased. However, the association at other skeletal regions between BMI, bone mass, and bone loss remains to be determined.

Since the sex-specific effects of BMI on the rapidly increasing prevalence of obesity are unclear, we aimed to research the association between BMI and therefore the risk of low BMD of the lumbar spine and femur separately. 


\section{PATIENTS AND METHODS}

\section{Study population and measurement of BMD}

The present retrospective study was conducted in the Institute of Nuclear Medicine and Allied Sciences (INMAS), Sylhet. People who underwent DEXA scan from January 2018 till June 2019 formed the study subjects. DEXA Scanning was performed by one technician, and the interpretation was done by two nuclear medicine physicians. Height and weight were measured. BMI was calculated from the height and weight recorded while performing the DEXA scan on the formula weight $(\mathrm{kg}) /[\text { height }(\mathrm{m})]^{2}$. The WHO criteria were used to classify respondents based on DEXA results.

\section{DEXA Output}

The output from the DEXA examination includes images of the body part scanned, quantitative data from the scanned area, including the bone mineral content (BMC), BMD, scanned area, T-scores, and Z-scores, and a graph of where the patient fits within the reference population.

Table I: The World Health Organization definitions of osteoporosis and osteopenia used to interpret lumbar spine, hip and forearm dual-energy $x$ ray absorptiometry (DXA) scan results

\begin{tabular}{ll}
\hline Terminology & T-score definition \\
\hline Normal & $\mathrm{T} \geqslant-1.0$ \\
Osteopenia & $-2.5<\mathrm{T}<-1.0$ \\
Osteoporosis & $\mathrm{T} \leqslant-2.5$ \\
\hline
\end{tabular}

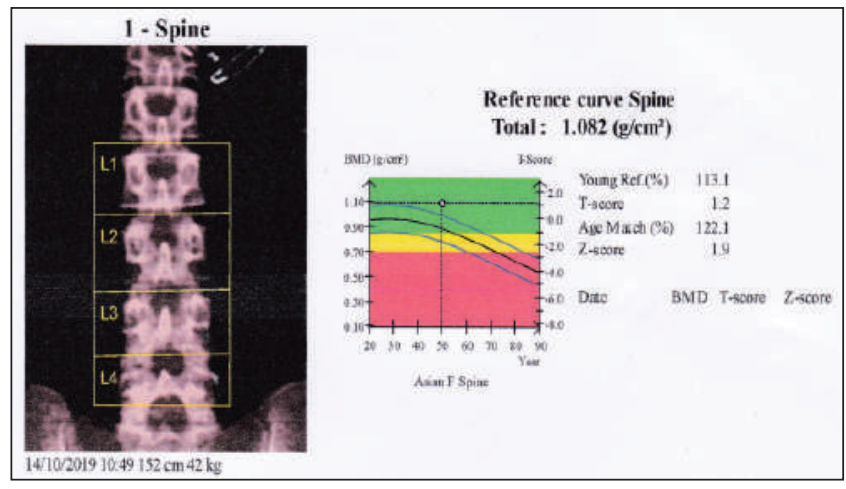

Figure 1: Normal BMD measurement of lumbar spine (L1-L4)

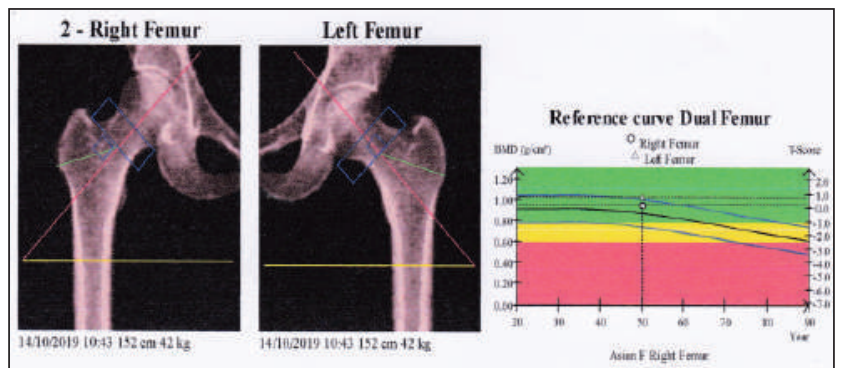

Figure 2: Normal BMD measurement at both femora

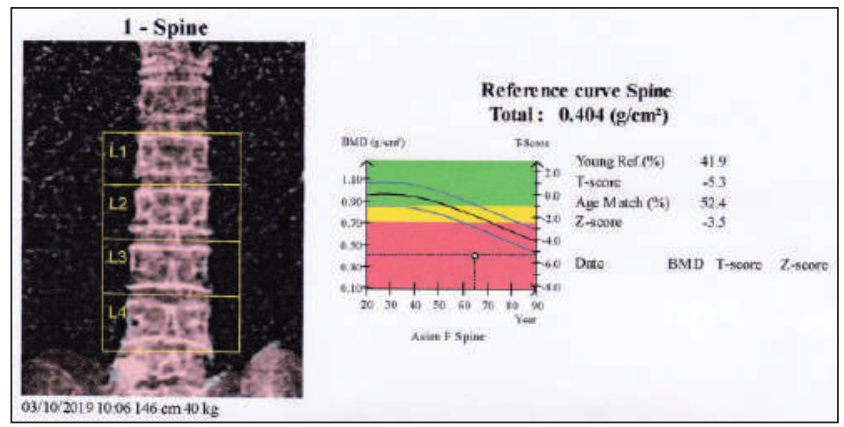

Figure 3: Very low BMD measurement (osteoporotic) at lumbar spine

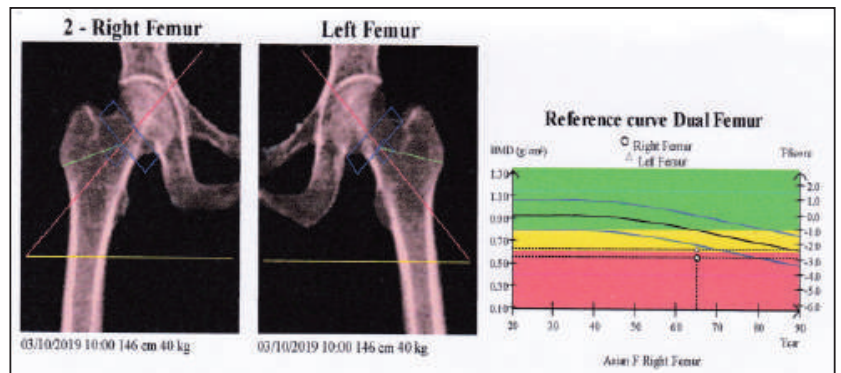

Figure 4: Very low BMD measurement (osteoporotic) at right femur

\section{Statistical analysis}

It includes the sociodemographic features and descriptive statistics to rule out the association between the DEXA scan results, BMI, and BMD status. First, the variables were analyzed in descriptive means and standard deviations. For continuous variables, including mean \pm standard deviation (SD), and categorical data were presented as count and percentage (\%). The statistical tests used in this study was chi-square tests. The variables considered were gender, age, and BMI. $\mathrm{P}$-value less than 0.05 was considered significant. We examined the relationship between BMI and $\mathrm{BMD}(\mathrm{T}$ score) by bivariate Pearson's correlation for each study. An IBM SPSS Statistics 25 performed the statistical analyses; two-tailed $\mathrm{p}<0.05$ was considered statistically significant. 


\section{RESULTS}

The study population consisted of 152 individuals. Distribution of gender showed that $84.9 \%$ were females and the remaining were males. Age ranged from 23 to 85 years. The mean and standard deviation of age was $57.73 \pm 13.30$ years. The mean and standard deviation of right femur T-score, left femur T-score and lumbar spine T-score was $-0.32 \pm 1.25),-0.37 \pm 1.28$ and $-1.67 \pm 1.62$ respectively. The mean and standard deviation of BMI was $24.07 \pm 4.19 \mathrm{~kg} / \mathrm{m} 2$ (Table 1).

Table 1: General traits of the participants (mean \pm standard deviation)

\begin{tabular}{lccc} 
& Min & Max & Mean \pm SD \\
\hline BMI & 15.11 & 38.21 & $24.07 \pm 4.19$ \\
Age (in years) & 23.00 & 85.00 & $57.73 \pm 13.30$ \\
Right Femur T-score & -4.70 & 4.00 & $-0.32 \pm 1.25$ \\
Left Femur T-score & -4.20 & 3.30 & $-0.37 \pm 1.28$ \\
Lumber Spine T-score & -5.50 & 3.10 & $-1.67 \pm 1.62$ \\
\hline
\end{tabular}

In this study, $52.6 \%$ of the patients had normal BMI. The respondents were classified in to two broad age groups, less than 60 and equal above 60years. About $49.3 \%$ in the study were in the age group of above 60 years. Approximately $52.6 \%$ of the subjects were normal, $30.3 \%$ patients were Overweight and $8.6 \%$ patients were obese. A detailed description is given in Table 2.

Table 2: Distribution of respondents according to age, gender, and BMI.

\begin{tabular}{llll} 
Variables & Group & Number & Percentage \\
\hline Gender & Male & 24 & 15.6 \\
& Female & 130 & 84.4 \\
BMI & Underweight & 13 & 8.6 \\
& Normal & 80 & 52.6 \\
& Overweight & 46 & 30.3 \\
& Obese & 13 & 8.6 \\
Age (in Years) & $<60$ & 77 & 50.7 \\
& $\geq 60$ & 75 & 49.3 \\
\hline
\end{tabular}

This study also showed that about $2 \%$ and $34.2 \%$ had osteoporosis in the right femur and lumbar spine, respectively. According to gender, female patients suffered from osteopenia and osteoporosis in the right femur of about $24.3 \%$ and $2 \%$ respectively and for lumbar spine $27 \%$ and $34.2 \%$ respectively. In male patients, $17.4 \%$ and $17.4 \%$ suffered from osteopenia and osteoporosis in lumbar spine respectively and rest had normal BMD. According to BMI from right femur, about $46.2 \%$ were osteopenia and under weight, among the patients with normal weight, $60.4 \%$ patients were with normal BMD. A detailed description is given in Table 3 .

Table 3: Distribution of bone mineral density according to independent factors for right femur and lumbar spine

\begin{tabular}{|c|c|c|c|c|}
\hline \multirow{2}{*}{ Independent factors } & \multicolumn{3}{|c|}{ Status of bone mineral density } \\
\cline { 3 - 5 } & \multicolumn{5}{|c|}{ Normal } & Osteopenia & Osteoporosis \\
\cline { 2 - 5 } & $\mathbf{N}$ (\%) & N (\%) & N (\%) \\
\hline \multirow{4}{*}{ Gender } & Male & $17(73.9)$ & $6(26.1)$ & $0(0)$ \\
\cline { 2 - 5 } & Female & $95(73.6)$ & $31(24)$ & $3(2.3)$ \\
\hline \multirow{3}{*}{ BMI } & Underweight & $5(38.5)$ & $6(46.2)$ & $2(15.4)$ \\
\cline { 2 - 5 } & Normal & $56(70)$ & $23(28.7)$ & $1(1.3)$ \\
\cline { 2 - 5 } & Overweight & $38(82.6)$ & $8(17.4)$ & $0(0)$ \\
\cline { 2 - 5 } & Obese & $13(100)$ & 0 & 0 \\
\hline Age (in Years) & $<60$ & $69(89.6)$ & $8(10.4)$ & $0(0)$ \\
\hline & $\geq 60$ & $43(57.3)$ & $29(38.7)$ & $3(4.0)$ \\
\hline \multirow{4}{*}{ Gender } & Total & $112(73.7)$ & $37(24.3)$ & $3(2.0)$ \\
\hline & Lule & $15(65.2)$ & $4(17.4)$ & $4(17.4)$ \\
\hline BMI & Female & $44(34.1)$ & $37(28.7)$ & $48(37.2)$ \\
\hline & Underweight & $2(15.4)$ & $1(7.7)$ & $10(76.9)$ \\
\hline & Normal & $27(33.8)$ & $25(31.3)$ & $28(35.0)$ \\
\hline & Overweight & $21(45.7)$ & $12(26.1)$ & $13(28.3)$ \\
\hline & Obese & $9(69.2)$ & $3(23.1)$ & $1(7.7)$ \\
\hline Age (in Years) & $<60$ & $38(49.4)$ & $20(26.0)$ & $19(24.7)$ \\
\hline & $\geq 60$ & $21(28.0)$ & $21(28.0)$ & $33(44.0)$ \\
\hline & Total & $59(38.8)$ & $41(27.0)$ & $52(34.2)$ \\
\hline
\end{tabular}

For further analysis, the whole group based on the DEXA scan result was divided as normal and low BMD. There were $112(73.7 \%)$ patients with normal BMD in right femur and $40(26.3 \%)$ with low BMD. In the lumbar spine, normal BMD was found in 59 (38.8\%) patients and $93(61.2 \%)$ patients with low BMD. Statistically significant association $(\mathrm{p}=<0.001$ in right femur and $p=0.022$ in lumbar spine) was found between different age groups and low BMD. There was significant association $(p=0.005)$ between gender and low BMD in lumbar spine but lack of association ( $\mathrm{p}=$ 0.978) in right femur. According to BMI compares to 
right femur, low BMD were found in $8(61.5 \%), 24$ (30.0\%), 8 (17.4\%) among underweight, normal and overweight patients but all the obese patient had normal BMD. According to BMI compare to lumbar spine, low BMD were found in $11(84.6 \%), 53(48.9 \%), 25$ $(54.3 \%), 4(30.8 \%)$ among underweight, normal, overweight and obese patients respectively. Association between BMI and BMD was found statistically significant $(p=0.001)$ and $(p=0.02)$ in right femur and Lumbar spine respectively. Low BMD was more marked in age group 60 or above in both right femur (42.7\%) and lumbar spine (72.0\%) compared to age group below 60 . The details are depicted in Table 4 .

Table 4: Association between bone mineral density and independent factors

\begin{tabular}{|c|c|c|c|c|}
\hline \multicolumn{5}{|c|}{ Femur } \\
\hline \multicolumn{2}{|c|}{ Independent factors } & \multicolumn{2}{|c|}{ Status of bone mineral density } & \multirow[t]{3}{*}{ P-value } \\
\hline & & Normal & Low BMD & \\
\hline & & $\mathrm{N}(\%)$ & $\mathrm{N}(\%)$ & \\
\hline & & \multicolumn{2}{|c|}{ Right Femur } & \multirow{3}{*}{0.978} \\
\hline \multirow[t]{2}{*}{ Gender } & Male & $17(73.9)$ & $6(26.1)$ & \\
\hline & Female & $95(73.6)$ & $34(26.4)$ & \\
\hline \multirow[t]{4}{*}{ BMI } & Underweight & $5(38.5)$ & $8(61.5)$ & \multirow{4}{*}{0.001} \\
\hline & Normal & $56(70.0)$ & $24(30.0)$ & \\
\hline & Overweight & $38(82.6)$ & $8(17.4)$ & \\
\hline & Obese & $13(100)$ & $0(0)$ & \\
\hline \multirow[t]{3}{*}{ Age (in Years) } & $<60$ & $69(89.6)$ & $8(10.4)$ & \multirow{3}{*}{$<0.0001$} \\
\hline & $\geq 60$ & $43(57.3)$ & $32(42.7)$ & \\
\hline & Total & $112(73.7)$ & $40(26.3)$ & \\
\hline \multicolumn{5}{|c|}{ Lumbar spine } \\
\hline \multirow[t]{2}{*}{ Gender } & Male & $15(65.2)$ & $8(34.8)$ & \multirow{2}{*}{0.005} \\
\hline & Female & $44(34.1)$ & $85(65.9)$ & \\
\hline \multirow[t]{4}{*}{$\overline{\mathrm{BMI}}$} & Underweight & $2(15.4)$ & $11(84.6)$ & \multirow{4}{*}{0.02} \\
\hline & Normal & $27(31.1)$ & $53(48.9)$ & \\
\hline & Overweight & $21(45.7)$ & $25(54.3)$ & \\
\hline & Obese & $9(69.2)$ & $4(30.8)$ & \\
\hline \multirow[t]{3}{*}{ Age (in Years) } & $<60$ & $38(49.4)$ & $39(50.6)$ & \multirow{2}{*}{0.007} \\
\hline & $\geq 60$ & $21(28.0)$ & $54(72.0)$ & \\
\hline & Total & $59(38.8)$ & $93(61.2)$ & \\
\hline
\end{tabular}

Correlation of BMI with lumbar spine $\mathrm{T}$ score, right femur and left femur $\mathrm{T}$ score were measured by Pearson's correlation coefficient test. Positive significant Pearson's correlation was observed between BMI with lumbar spine T score $(r=0.397 ; p=<0.001)$ Fig -1(a), BMI with right femur $\mathrm{T}$ score $(\mathrm{r}=0.347$; $\mathrm{p}=<0.001)$ fig-1(b) and BMI with left femur $\mathrm{T}$ score $(\mathrm{r}=0.382 ; \mathrm{p}=<0.001)$ fig $1(\mathrm{c})$.

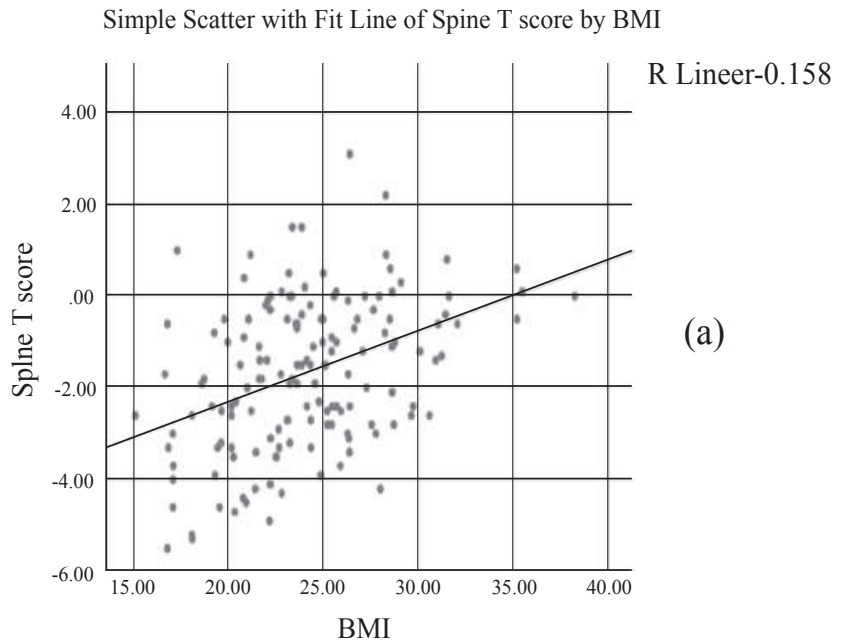

Scatter diagram with Right femur T score by BMI

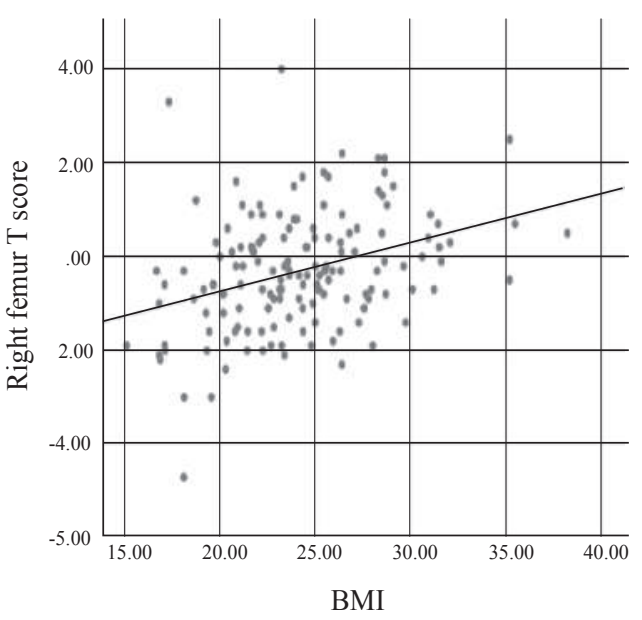

R Lineer-0.120

(b)

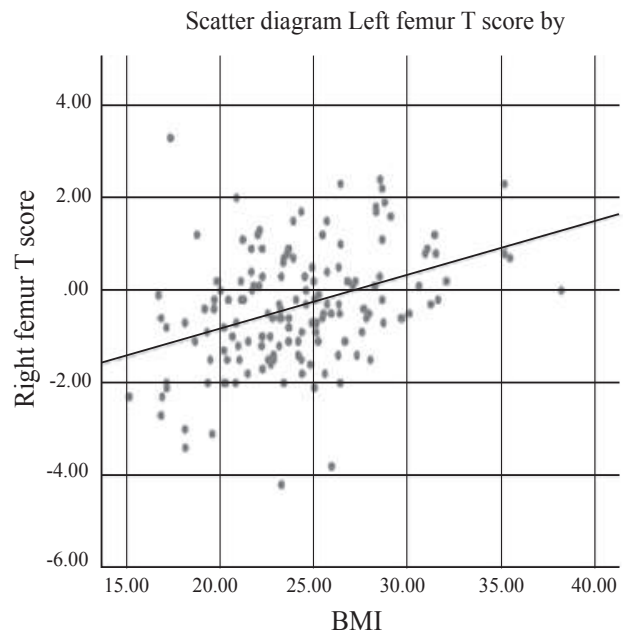

R Lineer-0.154

(c)

Figure 1: (a) Scatter diagram showing positive correlationbetween BMI $\left(\mathrm{kg} / \mathrm{m}^{2}\right)$ and lumbar spine T score. (b) Scatter diagram showing positive correlation between BMI $\left(\mathrm{kg} / \mathrm{m}^{2}\right)$ and right femur T score. (c) Scatter diagram showing positive correlation between BMI $\left(\mathrm{kg} / \mathrm{m}^{2}\right)$ and LeftFemur T score. 


\section{DISCUSSION}

DEXA is a recognized reference method for measuring BMD with acceptable precision errors and good accuracy. WHO has established DEXA as the best densitometric technique for determining BMD (5). DEXA allows accurate diagnosis of osteoporosis, fracture risk estimation, and monitoring of patients undergoing treatment. Identification of patients with low BMD is an important strategy to reduce the tendency for osteoporotic fractures.

This study revealed a positive association between T-score of BMD and BMI diagnosis in total sample. In addition, BMD of the right femur were not associated with gender. However, low BMD of lumbar spine and right femur were negatively related with age.

In this study, more than half of the population exhibited low BMD either osteopenia or osteoporosis. This finding is in accordance with previous studies $(6,7)$. Arround $61.2 \%$ and $26.3 \%$ showed low BMD in lumbar spine and right femur respectively, indicating that low BMD was more prevalent in lumbar spine. However, osteoporosis and osteopenia were found in $34.2 \%$ and $27.0 \%$ subjects in spine, $2 \%$ and $24.3 \%$ subjects in right femur indicating that osteoporosis was more common in spine but osteopenia was more prevalent in femur. In a study done by Mou et al (8) osteoporosis and osteopenia were found in $48.2 \%$ and $37.3 \%$ subjects in spine, $29.1 \%$ and $51.8 \%$ subjects in right hip, $34.6 \%$ and $52.7 \%$ subjects in left hip (9). also found osteoporosis and osteopenia in $49.5 \%$ and $36.4 \%$ study subjects in lumbar spine, in $24.2 \%$ and $38.4 \%$ study subjects in hip BMD measurements.

In age group $\geq 60$ years, low BMD in spine was $72.0 \%$ that is $42.29 \%$ higher compared to below 60 years' group (50.6\%). Fawzy et al. (3) found that the chance of low BMD among people with age 60 and above is 23 times higher compared to those with age 25-39. Moreover, this finding is comparable with those reported in the literature $(10,11)$. Among the 23 male patients, about one out of four were found low BMD. Moreover, we found some association between BMD with BMI and age as reported in the previous cross-sectional studies $(12,13)$.
However, significant association was observed between BMD and sex of the patients in lumbar spine only.

Several studies established positive association of higher body weight and / or BMI with bone mineral density or even protective effect against osteoporosis and fractures(3). We found that patients who are overweight had relatively better bone density than the low body weight patients. Overweight and obese subjects were more likely to have osteoporosis and osteopenia.Similar studies by Nguyen et al.(14)their associations with bone mineral density (BMD,Felson et al. (15) and Baheiraei et al. (16) also stated the consistent finding that lower BMI was associated with lower BMD. However, the result also shows that, elderlies showed an association with low BMD and the percentage of patients who were over 60 years was at higher risk of lower BMD. These findings are compatible with previous literature $(16,17)$.

This study is an attempt to address one of the major public health problems which can be controlled if preventive measures are taken at an early stage. This study has some limitations too. We couldn't consider all factors related with BMD. Thus, Future studies on BMD must be taken into consideration with detail history of other factors, including calcium intake, physical activity, lifestyle, sun exposure, alcohol consumption, smoking, reproductive factors, milk intake and parity of female patients are recommended, which could possibly confound the associations we observed.

\section{CONCLUSION}

This study suggests an association between BMD and BMI. The results of this study propose that normal and underweight person (BMI) have risk factors for the incidence of low BMD. This also suggested that increased body mass (independently of body fat percentage) may benefit BMD. We recommend increasing public awareness for the negative impact of the low BMD in Bangladesh.

\section{REFERENCES}

1. Trout NJ. Diseases of Bone. InHandbook of Small Animal Practice 2008 Jan 1 (pp. 778-793). WB Saunders.

2. Lems WF, Raterman HG. Critical issues and current challenges in osteoporosis and fracture prevention. An 
overview of unmet needs. Therapeutic Advances in Musculoskeletal Disease 2017 Dec;9(12):299-316. doi: $10.1177 / 1759720 X 17732562$

3. Fawzy T, Muttappallymyalil J, Sreedharan J, Ahmed A, Alshamsi SO, Al Ali MS, Al Balsooshi KA. Association between body mass index and bone mineral density in patients referred for dual-energy X-ray absorptiometry scan in Ajman, UAE. Journal of osteoporosis. 2011 Jan 1;2011. doi:10.4061/2011/876309

4. Fausto-Sterling A. The bare bones of sex: part 1-sex and gender. Signs: Journal of Women in Culture and Society 2005 Jan;30(2):1491-527. doi:10.1086/424932

5. Blake GM, Fogelman I. The role of DXA bone density scans in the diagnosis and treatment of osteoporosis. Postgraduate medical journal. 2007 Aug 1;83(982):509-17. doi:10.1136/pgmj.2007.057505

6. Achamrah N, Coëffier M, Jésus P, Charles J, Rimbert A, Déchelotte P, Grigioni S. Bone Mineral Density after Weight gain in 160 Patients with anorexia nervosa. Frontiers in nutrition 2017 Sep 29;4:46. doi:10.3389/fnut.2017.00046

7. Olmos JM, Valero C, del Barrio AG, Amado JA, Hernández JL, Menéndez-Arango J, González-Macías J. Time course of bone loss in patients with anorexia nervosa. International Journal of Eating Disorders 2010 Sep;43(6):537-42.doi:10.1002/eat.20731

8. Mou MH, Sultana S, Mutsuddy P, Sarmin S, Khan N, Biswas A. Assessment of Agreement of Wrist Bone Mineral Density with Spine and Hip Bone Mineral Density in Postmenopausal Women. Bangladesh Journal of Nuclear Medicine 2019 Dec 11;22(1):41-6. doi:10.3329/bjnm.v22i1.40504

9. Eftekhar-Sadat B, Ghavami M, Toopchizadeh V, Ghahvechi Akbari M. Wrist bone mineral density utility in diagnosing hip osteoporosis in postmenopausal women. Therapeutic advances in endocrinology and metabolism 2016 Dec;7(5-6):207-11. doi:10.1177/2042018816658164

10. Earnshaw SA, Cawte SA, Worley A, Hosking DJ. Colles' fracture of the wrist as an indicator of underlying osteoporosis in postmenopausal women: a prospective study of bone mineral density and bone turnover rate. Osteoporosis International. 1998 Feb 1;8(1):53-60. doi:10.1007/s001980050048

11. Patni R. Normal BMD values for Indian females aged 20-80 years. Journal of mid-life health. 2010 Jul;1(2):70. doi:10.4103/0976-7800.76215

12. Herrera A, Lobo-Escolar A, Mateo J, Gil J, Ibarz E, Gracia L. Male osteoporosis: A review. World journal of orthopedics 2012 Dec 18;3(12):223. doi:10.5312/wjo.v3.i12.223

13. Khosla S, Amin S, Orwoll E. Osteoporosis in men. Endocrine reviews 2008 Jun 1;29(4):441-64. doi:10.1210/er.2008-0002

14. Nguyen TV, Center JR, Eisman JA. Osteoporosis in elderly men and women: effects of dietary calcium, physical activity, and body mass index. Journal of bone and mineral research 2000 Feb;15(2):322-31. doi:10.1359/jbmr.2000.15.2.322

15. Felson DT, Zhang Y, Hannan MT, Anderson JJ. Effects of weight and body mass index on bone mineral density in men and women: the Framingham study. Journal of Bone and Mineral Research 1993 May;8(5):567-73. doi:10.1002/jbmr.5650080507

16. Baheiraei A, Pocock NA, Eisman JA, Nguyen ND, Nguyen $\mathrm{TV}$. Bone mineral density, body mass index and cigarette smoking among Iranian women: implications for prevention. BMC Musculoskeletal Disorders. 2005 Dec 1;6(1):34.doi:10.1186/1471-2474-6-34

17. Nguyen TV, Sambrook PN, Eisman JA. Bone loss, physical activity, and weight change in elderly women: the Dubbo Osteoporosis Epidemiology Study. Journal of bone and mineral research. 1998 Sep;13(9):1458-67. doi:10.1359/jbmr.1998.13.9.1458 